\title{
Aberrant expression of DNA damage response proteins is associated with breast cancer subtype and clinical features
}

\author{
Gulnur Guler • Cigdem Himmetoglu • Rafael E. Jimenez • Susan M. Geyer • \\ Wenle P. Wang - Stefan Costinean - Robert T. Pilarski - Carl Morrison • \\ Dinc Suren · Jianhua Liu · Jingchun Chen · Jyoti Kamal • \\ Charles L. Shapiro $\cdot$ Kay Huebner
}

Received: 19 August 2010/Accepted: 26 October 2010/Published online: 11 November 2010

(C) Springer Science+Business Media, LLC. 2010

\begin{abstract}
Landmark studies of the status of DNA damage checkpoints and associated repair functions in preneoplastic and neoplastic cells has focused attention on importance of these pathways in cancer development, and inhibitors of repair pathways are in clinical trials for treatment of triple negative breast cancer. Cancer heterogeneity suggests that specific cancer subtypes will have distinct mechanisms of DNA damage survival, dependent on biological context. In this study, status of DNA damage response (DDR)-associated proteins was examined in breast cancer subtypes in association with clinical features;
\end{abstract}

Cigdem Himmetoglu, Rafael E. Jimenez, and Susan M. Geyer are equal contributors.

Electronic supplementary material The online version of this article (doi:10.1007/s10549-010-1248-6) contains supplementary material, which is available to authorized users.

G. Guler · C. Himmetoglu

Department of Pathology, Hacettepe University, Ankara, Turkey

G. Guler · D. Suren

Department of Pathology, Ataturk Research and Education Hospital, Ankara, Turkey

R. E. Jimenez · W. P. Wang · C. Morrison Department of Pathology, The Ohio State University Medical Center, Columbus, OH, USA

S. M. Geyer · R. T. Pilarski - C. L. Shapiro

Department of Internal Medicine, The Ohio State University

Medical Center, Columbus, OH, USA

S. Costinean $\cdot$ K. Huebner $(\bowtie)$

Department of Molecular Virology, Immunology and Medical

Genetics, The Ohio State University Medical Center,

Columbus, OH, USA

e-mail: kay.huebner@osumc.edu
479 breast cancers were examined for expression of DDR proteins $\gamma \mathrm{H} 2 \mathrm{AX}$, BRCA1, pChk2, and p53, DNA damagesensitive tumor suppressors Fhit and Wwox, and Wwoxinteracting proteins Ap2 $\alpha$, Ap2 $\gamma$, ErbB4, and correlations among proteins, tumor subtypes, and clinical features were assessed. In a multivariable model, triple negative cancers showed significantly reduced Fhit and Wwox, increased p53 and Ap2 $\gamma$ protein expression, and were significantly more likely than other subtype tumors to exhibit aberrant expression of two or more DDR-associated proteins. Disease-free survival was associated with subtype, Fhit and membrane ErbB4 expression level and aberrant expression of multiple DDR-associated proteins. These results suggest that definition of specific DNA repair and checkpoint defects in subgroups of triple negative cancer might identify new treatment targets. Expression of Wwox and its interactor, ErbB4, was highly significantly reduced in metastatic tissues vs. matched primary tissues, suggesting

J. Liu · J. Chen · J. Kamal

Information Warehouse, The Ohio State University Medical

Center, Columbus, OH, USA

Present Address:

R. E. Jimenez

Division of Anatomic Pathology, Mayo Clinic,

Rochester, MN, USA

Present Address:

W. P. Wang

Department of Pathology, VA Medical Center at Baltimore,

Baltimore, MD, USA

Present Address:

C. Morrison

Department of Pathology \& Laboratory Medicine,

Division of Molecular Pathology, Roswell Park Cancer Institute,

Buffalo, NY, USA 
that Wwox signal pathway loss contributes to lymph node metastasis, perhaps by allowing survival of tumor cells that have detached from basement membranes, as proposed for the role of Wwox in ovarian cancer spread.

Keywords Triple negative breast cancer - DNA damage response proteins - Lymph node metastases - Fhit .

Wwox · Tissue microarrays

\section{Introduction}

Chromosome fragile sites are preferential targets of replication stress, resulting in deletions involving encoded fragile genes $[1,2]$. The most commonly altered fragile sites are FRA3B/FHIT and FRA16D/WWOX at chromosomes 3p14.2 and 16q23.3. Fhit and Wwox protein expression is coordinately lost or reduced in $\sim 2 / 3$ of breast cancers [3] and loss is more frequent in ER/PR negative breast tumors [4]. Coordinate loss of Fhit and Wwox also occurs in ductal carcinoma in situ tissues [5], suggesting early loss during breast carcinogenesis.

Several lines of investigation have focused our interest on expression of DDR-associated proteins in breast cancer and how DNA damage-targeted tumor suppressor loss participates in DDR checkpoint activation and repair processes: (1) Reports of activated DDR checkpoints in preneoplastic lesions, accompanied by allelic FHIT deletions [6-8] and loss of expression of Fhit protein in early lesions [9-11], coupled with our knowledge that Fhit expression loss contributes to aberrant DDR [12], suggested that deletions at the FHIT gene could activate the DDR and reduction in Fhit protein expression could contribute to neoplastic progression. (2) The discovery that BRCA1/2 deficient breast cancer-derived cell lines were sensitive to killing by inhibitors of PARP enzymatic activity [13, 14], through a synthetic lethal mechanism involving loss of homologous recombination repair (HRR) and blocking of other repair pathways by PARP inhibition [15-17]. (3) BRCA1-deficient breast cancers are mostly triple negative (TN), a subtype associated with defects in some types of DNA repair [18] and endowed with "BRCAness" [19], and Fhit expression is lost in $\sim 90 \%$ of BRCA1 and 2-mutated breast cancers [20-22]. Thus, we were interested in how loss of expression of Fhit and Wwox, might contribute to "BRCAness" and to responses to aberrant DDR checkpoints or repair pathways.

Chk2 and Chk1, downstream targets of ATM and ATR, have roles in regulation of checkpoint responses [23, 24] and the absence of expression of wild type ATR or Chk1 leads to accumulation of deletions and rearrangements of fragile sites [25]. The occurrence of DNA double-strand breaks (DSBs) is followed by phosphorylation of histone H2AX by ATM or ATR; the phosphorylated protein, $\gamma \mathrm{H} 2 \mathrm{AX}$, recruits, and localizes DNA repair proteins [26], including BRCA1 [27], to the DNA breaks.

In a study of 837 breast cancers on a tissue microarray (TMA), we observed that TN tumors showed significantly reduced Fhit and Wwox expression [4]. We then analyzed the expression of DDR-associated proteins $\gamma \mathrm{H} 2 \mathrm{AX}$, pChk2, and $\mathrm{p} 53$ in these cases and found that increased nuclear expression of $\gamma \mathrm{H} 2 \mathrm{AX}, \mathrm{pChk} 2$, and p53 was significantly more frequent in TN tumors [GG, CH, REJ, WPW, SC, RTP, CLS, KH, unpublished results]. We have continued similar studies on an independent breast cancer cohort, including all breast cancer subtypes [28] and matched primary and metastatic cases, with linked clinical and follow-up data, to gain a better understanding of the role of activated DDR-associated proteins in breast cancer subtypes and outcomes.

\section{Materials and methods}

\section{Construction of the breast cancer TMAs}

The studies were approved by the Ohio State University Institutional Review Board for studies of human subjects. Tissue Archive Services and Information Warehouse personnel of the Ohio State University Medical Center, acting as "honest brokers", anonymized all cases by removing identifiers and assigning random numbers before supplying slides, blocks, and linked clinical information to investigators.

\section{The SFBCAS TMA}

Breast cancer cases (824) from prior to 1998, were selected from $\sim 4000$ women who contributed pathological and clinical outcome data to the National Comprehensive Cancer Network (NCCN) breast cancer database [29]. Selection criteria included all invasive breast cancers for which clinical information, including stage, grade, histologic type, treatment, site of first recurrence, and disease-free and overall survival were available. The parrafin-embedded tissue blocks were reviewed by pathologists (CM and REJ) and 564 were acceptable for the TMA, 303 for which there was tumor only, 226 with tumor and metastases, and 35 with only metastatic tissue. Cores $(0.6 \mathrm{~mm})$ from each tumor and metastasis were placed in quadruplicate blocks, with 50 assorted control tissues. The clinical information for the primary breast cancers included histological tumor type, grade and ER, PR, and ErbB2 status of tumors abstracted from clinical records and pathology reports. 
Immunohistochemical analysis

BRCA1, pChk2, $\gamma$ H2AX, p53, Fhit, Wwox, Wwox-interacting proteins (Ap2 $\gamma$, Ap2 $\alpha$, ErbB4), ErbB3, CK5/6, EGFR immunostainings were performed on TMA sections as described [3-5]. Specific antisera used, staining methods and detection kits are listed in Table 1. Expression of Fhit, Wwox, and CK5/6 was cytoplasmic, Ap2 $\alpha$, Ap2 $\gamma$, pChk2, and $\gamma \mathrm{H} 2 \mathrm{AX}$ nuclear, EGFR, ErbB3, and ErbB4 cytoplasmic and membranous, and BRCA1 nuclear and cytoplasmic. Cytoplasmic expression in $\geq 10 \%$ of tumor cells for CK5/6, membranous staining in $\geq 10 \%$ of tumor cells for EGFR and nuclear staining in $\geq 10 \%$ for Ap2 $\alpha$, Ap $2 \gamma$, was accepted as positive. Fhit and Wwox staining in tumors was scored according to intensity: absent, highly reduced, reduced staining, or strong expression $[4,5,30]$, though final scores were collapsed to two categories (lost/very reduced vs. strong/moderate expression for some statistical modeling); $>50 \%$ of cells for nuclear $\gamma \mathrm{H} 2 \mathrm{AX}$ and $>25 \%$ of cells for nuclear pChk2, $\geq 50 \%$ strong expression of $\mathrm{p} 53$, any membrane staining of ErbB3 and ErbB4 was accepted as positive. BRCA1 nuclear expression was scored as $<$ or $>90 \%$ and reduced cytoplasmic BRCA1, ErbB3, and ErbB4 expression was noted when present. Four pathologists (GG, REJ, WPW, SC) scored the slides and were blinded to the breast cancer subtype; two pathologists (GG, $\mathrm{CH})$ converted scores to numbers, selected cut off values for each marker and entered data into excel and SPSS files. The 423 breast cancers that could be scored were divided into subtypes of breast cancer as defined by their IHC profiles using designated stains [31, 32]. These include luminal A (ER and/or PR positive, ErbB2 negative); luminal B (ER and/or PR positive, ErbB2 positive); ErbB2+++ (ER and
PR negative, ErbB2 IHC/FISH+++); basal-like TN (ER, PR, ErbB2 negative and CK5/6 and/or EGFR positive); and TN non-basal (ER, PR, ErbB2, CK5/6, EGFR negative). Since ErbB2 status was not available for some tumors, we also evaluated tumors by ER/PR status: luminal (ER and/or PR positive) vs. not (ER and PR negative), as well as luminal vs. TN vs. ErbB2 +++ for ER and PR negative tumors for which ErbB2 status was available.

\section{Statistical analysis}

Not all marker or clinical data were available on all subjects, and percentages refer to cases for which data for a specific variable were available. Associations between categorical variables (e.g., marker score data, menopausal status, ER status) were evaluated using chi-square or Fisher exact tests. McNemar tests were used to analyze concordance in marker expression in tumor tissue and matching metastatic tissue.

Relationships of marker expression and clinical features were evaluated in relation to disease subtype using univariate and multivariable logistic regression models. Variable selection in the multivariable models was explored by the leaps and bounds approach [33]. We also assessed potential multivariable models based on the univariate logistic regression models.

Disease-free survival (DFS) was assessed from the time patients were disease-free to date of recurrence and/or death. Patients with metastases at diagnosis were excluded from DFS analyses and only subjects with stage I-III tumors at diagnosis were included. Kaplan-Meier and Cox regression models were used to evaluate DFS, where differences in DFS distributions were evaluated based on

Table 1 Primary antisera and detection kits used in immunohistochemical studies

\begin{tabular}{llll}
\hline Primary antiserum & Description & Dilution & Detection kit \\
\hline Fhit & Rabbit $\left(\right.$ Huebner lab $^{\mathrm{a}}$ ) & $1 / 5000$ & Vectastain Elite kit (Vector Laboratories, Burlingame, CA) \\
Wwox & Rabbit $\left(\right.$ Huebner lab $\left.{ }^{\mathrm{a}}\right)$ & $1 / 7000$ & Vectastain Elite kit \\
Ap2 $\gamma$ & Mouse (Santa Cruz, 6E4/4) & $1 / 75$ & Universal LSAB+ (Dako, Carpinteria, CA) \\
Ap2 $\alpha$ & Mouse (Santa Cruz, 3B5) & $1 / 75$ & Universal LSAB+ \\
$\gamma$ H2AX & Rabbit (Bethyl Labs, IHC-00059) & $1 / 500$ & Vector Impress (Vector Laboratories) \\
p53 & Mouse (Dako, M7001) & $1 / 50$ & Universal LSAB+ \\
pChk2 & Rabbit (Abcam, Ab38461) & $1 / 100$ & Vector Impress \\
CK5/6 & Mouse (Dako, D5/16 B4) & $1 / 50$ & Universal LSAB+ \\
EGFR & Mouse (Dako, PharmDx Kit, 2-18C9) & Neat & Dako, Envision Plus, included in kit \\
ErbB4 & Rabbit (Neomarkers, RB-9045-R7) & $1 / 75$ & UltraTek HRP Anti-Polyvalent Lab Pack (ScyTek Laboratories, \\
& & & Cache, Utah,) \\
BRCA1 & Mouse (Calbiochem, MS110) & $1 / 25$ & Universal LSAB+ \\
ErbB3 & Mouse (Neomarkers, H3.105.5) & $1 / 25$ & UltraTek HRP Anti-Polyvalent Lab Pack \\
\hline
\end{tabular}

a The features of the antiserum have been described in detail $[3,7]$ 
clinical characteristics and marker expression. The $P$ values reported in relation to DFS correspond to log rank tests unless otherwise noted.

Since we simultaneously evaluated multiple markers along with clinical characteristics of interest, we corrected for multiple comparisons using the Benjamini-Hochberg method to control for false discovery rates. Statistical significance was defined by ranking observed $P$ values from smallest to largest and comparing each $i$ th $P$ value to $(i / m)^{*} Q$, where $m=$ number of $P$ values for that set of analyses and $Q$ is the chosen constraint for false discovery rate (FDR, here set to 0.05). All analyses were conducted using PASW Statistics (SPSS) v. 18 and R version 2.9.0.

\section{Results}

Breast cancer characteristics

Table 2 lists the characteristics of cases included in the $S F B C A S$ TMA. Due to missing clinical data, primarily

Table 2 Characteristics of the SFBCAS TMA cases $(n=423)$

\begin{tabular}{|c|c|}
\hline & Number of patients \\
\hline \multicolumn{2}{|l|}{ Race } \\
\hline Caucasian & 368 \\
\hline African American & 48 \\
\hline Other & 4 \\
\hline \multicolumn{2}{|l|}{ Menopause status } \\
\hline Pre-menopausal & 150 \\
\hline Post-menopausal & 227 \\
\hline \multicolumn{2}{|l|}{ Grade } \\
\hline I & 33 \\
\hline II & 175 \\
\hline III & 174 \\
\hline \multicolumn{2}{|l|}{ ER status } \\
\hline Negative & 102 \\
\hline Positive & 307 \\
\hline \multicolumn{2}{|l|}{ PR status } \\
\hline Negative & 135 \\
\hline Positive & 268 \\
\hline \multicolumn{2}{|l|}{ ErbB2 status } \\
\hline Negative & 234 \\
\hline $3+$ IHC or FISH+ & 77 \\
\hline \multicolumn{2}{|l|}{$\mathrm{TN}$} \\
\hline No & 340 \\
\hline Yes & 47 \\
\hline \multicolumn{2}{|l|}{ Basal } \\
\hline No & 266 \\
\hline Yes & 33 \\
\hline
\end{tabular}

Table 2 continued

\begin{tabular}{|c|c|}
\hline & Number of patients \\
\hline \multicolumn{2}{|l|}{ ER/PR status } \\
\hline ER and PR neg & 99 \\
\hline $\mathrm{ER}+, \mathrm{PR}+$, or both & 301 \\
\hline \multicolumn{2}{|l|}{ Subtype } \\
\hline Luminal A & 179 \\
\hline Luminal B & 47 \\
\hline ErbB2 +++ & 29 \\
\hline $\mathrm{TN}$ & 47 \\
\hline \multicolumn{2}{|l|}{ Age at diagnosis } \\
\hline$\leq 40$ & 47 \\
\hline $41-50$ & 135 \\
\hline$>50$ & 238 \\
\hline \multicolumn{2}{|l|}{ Histology } \\
\hline Invasive ductal & 313 \\
\hline Invasive lobular & 27 \\
\hline Mixed ductal lobular & 35 \\
\hline Other & 48 \\
\hline \multicolumn{2}{|l|}{ Death } \\
\hline No & 398 \\
\hline Yes & 22 \\
\hline \multicolumn{2}{|l|}{ Cause of death } \\
\hline N/A (alive) & 398 \\
\hline Cancer-related & 20 \\
\hline Other causes & 2 \\
\hline \multicolumn{2}{|l|}{ Recurrence $^{\mathrm{a}}$} \\
\hline No & 245 \\
\hline Yes & 85 \\
\hline \multicolumn{2}{|l|}{ Type of 1 st recurrence ${ }^{a}$} \\
\hline In situ & 4 \\
\hline Local/Regional & 19 \\
\hline Distant & 60 \\
\hline Type unknown & 2 \\
\hline \multicolumn{2}{|l|}{ Metastatic tissue type } \\
\hline Lung nodule & 1 \\
\hline Lymph node(s) & 105 \\
\hline Skin & 3 \\
\hline N/A (no mets tissue) & 314 \\
\hline
\end{tabular}

${ }^{a}$ Does not include 93 cases that were never disease-free, those unknown if ever disease-free and those with missing recurrence information

ErbB2 +++ status, subtype could be determined in only 302 cases. Most cancers $60 \%$ (179/302) were classified as luminal A, 15\% (47/302) were luminal B, 10\% (29/302) ErbB2+++, and 15\% (47/302) TN. Combining luminal A and $B$ groups (ER and/or PR positive) allowed classification of more tumors: $80.4 \%(312 / 388)$ were ER and/or PR positive, $7.5 \%$ (29/388) ErbB2+++, 12.1\% (47/398) TN. Among the $47 \mathrm{TN}$ cases, CK5/6 and EGFR expression 
scores were available in all but 4 . Of the remaining 43, 33 (76.8\% showed a basal-like phenotype as determined by EGFR and CK5/6 staining. The TMA analyses included 109 subjects with both tumor tissue and metastatic tissue; $96 \%$ of metastatic tissues were from lymph nodes (Table 2).

As noted in earlier studies, there were significant differences in the ages at diagnosis by breast cancer subtype; the median age for $\mathrm{TN}$ cases was 47 years, while for luminal A, B, and ErbB2+++ median ages were 55, 51, and 52 years, respectively $(P=0.003)$.

DDR-associated protein expression in breast cancer

\section{The SFBCAS TMA}

There were data on 423 breast cancer subjects, including biochemical markers determined by IHC and integrated clinical data (Table 2 for summary). We assessed associations among pairs of proteins in this TMA (Supplementary Table S1): pChk2 and $\gamma \mathrm{H} 2 \mathrm{AX}$ expression were highly positively correlated only with each other $(P<0.00001)$; BRCA1 nuclear expression was significantly positively correlated with expression of cytosolic ErbB3 $(P=$ 0.00004 ) and with Fhit and Wwox expression (each $P=$ 0.02 ), indications of an intact HRR pathway in cancers expressing nuclear BRCA1. Expression of the transcription factor Ap $2 \gamma$ was highly, positively associated with expression of pChk2 and p53 $(P<0.001)$.

The DDR checkpoint proteins, $\gamma \mathrm{H} 2 \mathrm{AX}$, pChk2, and p53, were expressed more frequently in $\mathrm{TN}$ and basal-like cancers vs. other subtypes (Fig. 1 for illustration of results, Fig. 2 for representative photos of IHC results). As observed by others [19], we find that TN tumors frequently show reduced expression of BRCA1. The bar graph in Fig. 1 shows that highly positive BRCA1 expression $(90 \%$ of cells with nuclear expression) was rare in the TN tumors
(Table S2 lists expression scoring results for specific markers relative to clinical features). By univariate modeling, BRCA1 nuclear expression was significantly, inversely associated with ER/PR negativity $(P=0.0004)$ and specifically with TN breast cancer subtype $(P=0.009$, Table 3). p53 expression was also highly correlated with TN and basal-like subtypes $(P<0.00001)$.

In order to investigate more broadly the association of alterations to expression of DDR proteins in $\mathrm{TN}$ breast cancers, a DDR score was devised, based on frequency of altered or activated expression of nuclear BRCA1, $\gamma \mathrm{H} 2 \mathrm{AX}$, pChk2, Fhit, p53; i.e., proteins involved in recognition of DNA breaks $(\gamma \mathrm{H} 2 \mathrm{AX})$, in checkpoint activation in response to breaks (pChk2, p53), or DNA repair (Fhit, BRCA1). The number of deleteriously expressed markers was summed, where reduced nuclear BRCA1 or Fhit, or elevated $\gamma \mathrm{H} 2 \mathrm{AX}$, p53, or pChk2 were considered deleterious. The median number of markers with deleterious expression was 2 . TN cancers had a median of 3 aberrantly expressed markers vs. non-TN cancers (median $=3$ vs. $2, P<$ 0.0001). Across the 279 tumors with data for all 5 markers, only 4 had deleterious expression of all 5 markers (2 luminal, $2 \mathrm{TN}) ; 17$ had no deleterious expression of any markers (all luminal) (data for stage I-III cases with recurrences summarized in Table S3). Based on logistic regression models, DDR score (0 vs. 1 vs. 2 vs. 3 vs. 4 vs. 5) was significantly associated in the univariate setting with TN status $(P<0.00001)$. Analyses of the DDR protein scores supported a collapsing of the scores into two groups: $0-1$ vs. $2-5$; this collapsed grouping of $0-1$ vs. $2-5$ was also significantly associated with $\mathrm{TN}$ status $(\mathrm{OR}=6.2$, $P=0.003$, Table 3 ). By this assay, TN cancers were $6 \times$ more likely to exhibit aberrant expression of 2 or more DDR-associated proteins. The distribution of scores between TN and non-TN subjects is shown in the box plot in Fig. 3.

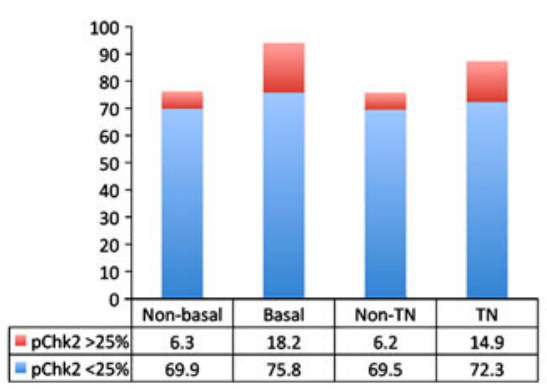

Fig. 1 Graphical representation of expression of DDR proteins in TN cancers. In studies of the breast cancers on the SFBCAS TMA, DDR proteins were expressed more frequently in TN and basal-like tumors. The numbers to the lower left of each graph represent the cut-off percentages for scoring a tumor positive or negative; i.e., for $\mathrm{pChk} 2$, tumors were scored positive if $>25 \%$ of nuclei were positive for
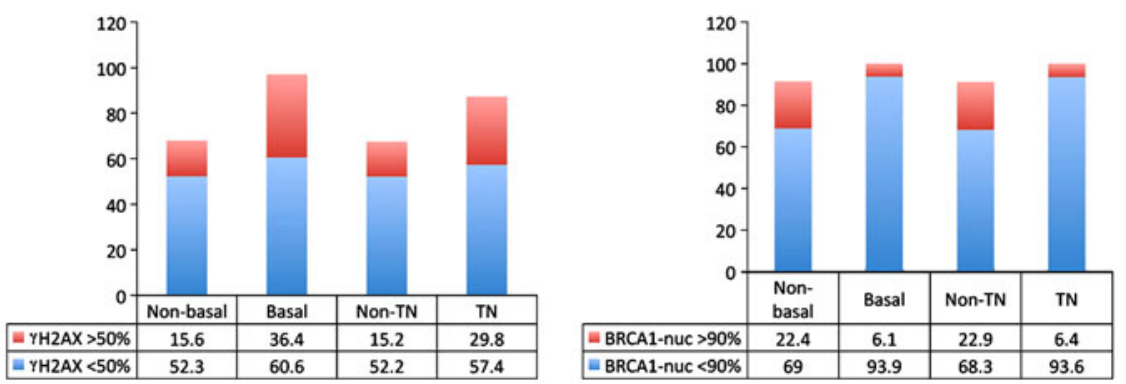

expression and were scored negative if $<25 \%$ of nuclei were expressing pChk2. For $\gamma \mathrm{H} 2 \mathrm{AX}$ the cut-off was at $50 \%$ and for BRCA1 at $90 \%$. Because percentages were calculated using denominators that included cases for which scores were not available, the percentages will not necessarily sum to $100 \%$ across the expression groups for individual markers 


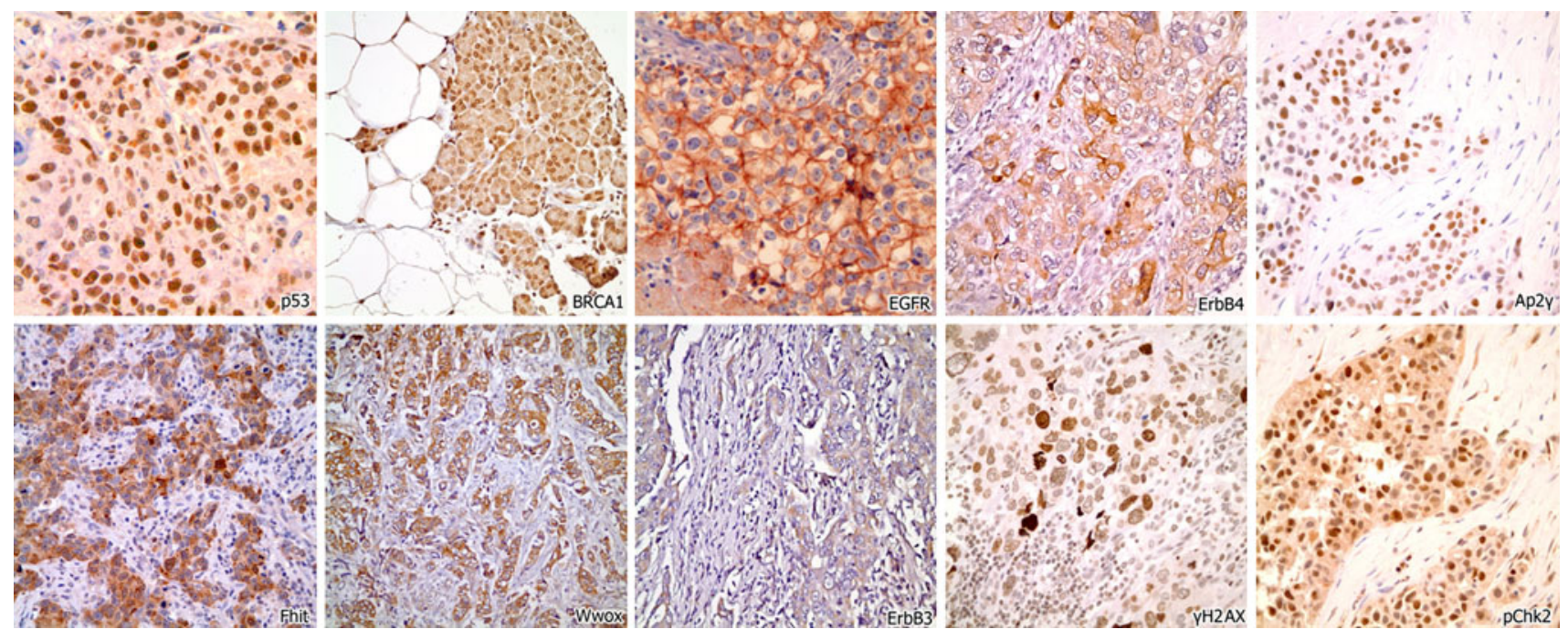

Fig. 2 Expression of specific proteins in breast cancers by IHC analysis. Photographs $(\times 400)$ were taken of immunohistochemical detection of each of the specific proteins assessed on the TMA and representative photographs are shown for each protein

Table 3 Univariate associations of markers with subtype and stage

$P$ values reflecting assessments of univariate associations of each marker were calculated from univariate logistic regression models, where the odds ratio estimates (OR est) are the exponential of the parameter estimates for that variable in the model

\begin{tabular}{|c|c|c|c|c|c|c|}
\hline \multirow[t]{2}{*}{ Marker } & \multicolumn{2}{|c|}{ TN vs. other } & \multicolumn{2}{|c|}{ Basal vs. other } & \multicolumn{2}{|c|}{ Stage II/III vs. I } \\
\hline & OR est & $P$ value & OR est & $P$ value & OR est & $P$ value \\
\hline Ap $2 \gamma$ & 4.53 & 0.00005 & 4.75 & 0.0003 & 1.01 & 0.98 \\
\hline CK5/6 & 5.67 & $<0.00001$ & 10.61 & $<0.00001$ & 1.32 & 0.40 \\
\hline pChk2 & 1.52 & 0.08 & 1.64 & 0.051 & 0.79 & 0.57 \\
\hline$\gamma \mathrm{H} 2 \mathrm{AX}$ & 1.33 & 0.12 & 1.42 & 0.08 & 1.15 & 0.38 \\
\hline BRCA1 nuc & 0.20 & 0.009 & 0.20 & 0.03 & 0.57 & 0.037 \\
\hline ErbB3 cyto & 0.29 & 0.0002 & 0.36 & 0.007 & 0.56 & 0.016 \\
\hline ErbB3 membr & 0.27 & 0.007 & 0.40 & 0.07 & 1.02 & 0.92 \\
\hline ErbB4 cyto & 2.18 & 0.03 & 2.53 & 0.035 & 0.98 & 0.95 \\
\hline ErbB4 membr & 2.1 & 0.02 & 2.2 & 0.03 & 0.80 & 0.35 \\
\hline Fhit & 0.11 & 0.0003 & 0.17 & 0.005 & 0.47 & 0.001 \\
\hline Wwox & 0.28 & 0.0002 & 0.28 & 0.001 & 0.66 & 0.16 \\
\hline p53 & 6.1 & $<0.00001$ & 6.2 & $<0.00001$ & 1.95 & 0.043 \\
\hline EGFR & 11.0 & $<0.00001$ & 29.4 & $<0.00001$ & 1.81 & 0.063 \\
\hline DDR score $(0-1$ vs. $2+)$ & 6.2 & 0.003 & 4.4 & 0.017 & 2.25 & 0.005 \\
\hline
\end{tabular}

Tumor suppressors and interacting proteins in association with breast cancer subtypes

As shown in Table 3, expression of various proteins was significantly associated with subtype groups in the univariate setting: lost or reduced Fhit and Wwox expression was strongly associated with $\mathrm{TN}$ tumors $(P=0.0003$ and $0.0002)$, as were absence of ErbB3 cytosolic expression and positive membrane expression of ErbB4 (Table 3). Other significant factors for TN status in the univariate setting were: Ap2 $\gamma \quad(P=0.00005)$, reduced BRCA1 nuclear expression $(P=0.009)$ and p53 $(P<0.00001)$ expression.
When protein expression markers were evaluated in the multivariable setting in relation to TN status (Table 4), four markers remained significant: reduced Wwox and Fhit $(P=0.002$ and 0.03 ), and p53 and Ap2 $\gamma$ positivity (both $P=0.004)$. Overall, Wwox, Ap $2 \gamma$, and p53 remained significant across multivariable models for each of the subtype groupings (ER/PR negative, TN, and basal-like).

Primary tumors and metastases

In analyses for level of agreement between markers in tumor vs. metastatic tissue, expression of several proteins were significantly discordant, as shown in Table 5 (Fig. 4 


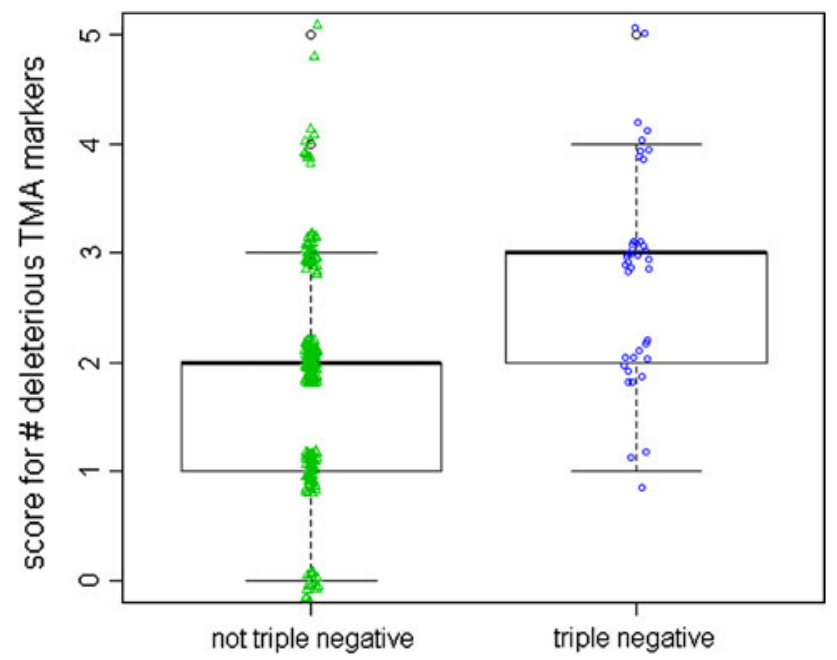

Fig. 3 Boxplot of DDR scores, for number of aberrantly expressed DDR-associated proteins in TN vs. non-TN breast cancers. The DDRassociated proteins assessed were: altered or activated expression of nuclear BRCA1, $\gamma \mathrm{H} 2 \mathrm{AX}$, pChk2, Fhit, p53; i.e., proteins involved in recognition of DNA breaks $(\gamma \mathrm{H} 2 \mathrm{AX})$, in checkpoint activation in response to breaks (pChk2, p53), or in DNA repair (Fhit, BRCA1)

Table 4 Multivariable logistic regression modeling

\begin{tabular}{llllll}
\hline Marker & \multicolumn{2}{l}{ TN vs. other } & & \multicolumn{2}{l}{ Basal vs. other } \\
\cline { 2 - 3 } & OR est. $^{\mathrm{a}}$ & $P$ value & & OR est. ${ }^{\mathrm{a}}$ & $P$ value \\
\hline Intercept & 0.29 & 0.02 & & 0.14 & 0.002 \\
Ap2 $\gamma$ & 4.5 & $\mathbf{0 . 0 0 4}$ & & 4.6 & $\mathbf{0 . 0 0 5}$ \\
ErbB3 cyto & 0.45 & 0.07 & & 0.50 & 0.14 \\
ErbB3 membr & 0.26 & 0.07 & & 0.35 & 0.17 \\
Fhit & 0.20 & $\mathbf{0 . 0 3}$ & & 0.30 & 0.12 \\
Wwox & 0.22 & $\mathbf{0 . 0 0 2}$ & & 0.27 & $\mathbf{0 . 0 1}$ \\
p53 & 4.1 & $\mathbf{0 . 0 0 4}$ & 3.0 & $\mathbf{0 . 0 3}$ \\
\hline
\end{tabular}

${ }^{a}$ OR est from these models reflect the exponential of the multivariable logistic regression model parameter estimates. In looking at the models of TN vs. other, and basal-like vs. other, these same variables that are statistically significant in the multivariable models shown above were also significant factors in multivariable models using an all subsets approach to variable selection (leaps and bounds method [33]). The only difference was that in the all subsets methods, the ErbB3 cytoplasmic score was also a significant identified marker for basal-like vs. other. Also, in the all subsets method, the addition of the Fhit score did not contribute much to the overall model in determining TN vs. other

for representative photographs of protein expression in matched primary and metastatic sections). Expression of Wwox was highly significantly reduced in the metastatic tissues $(P<0.0001)$ vs. the primary tumor tissue; loss of cytosolic and membrane ErbB4 expression was also associated with occurence of metastases $(P=0.002$ and $0.004)$, as was BRCA1 nuclear expression $(P=0.003)$.
Table 5 Protein expression differences in primary tumors vs. metastases

\begin{tabular}{|c|c|c|c|}
\hline \multirow[t]{2}{*}{ Protein } & \multicolumn{3}{|c|}{ Cases with tumor and metastatic tissue } \\
\hline & Tumor tissue & Metastatic tissue & $P$ value* \\
\hline \multicolumn{4}{|c|}{ ErbB4 cyt } \\
\hline 0 & 36 & 60 & \multirow[t]{2}{*}{0.002} \\
\hline 1 & 70 & 46 & \\
\hline \multicolumn{4}{|c|}{ ErbB4 membr } \\
\hline 0 & 65 & 85 & \multirow[t]{2}{*}{0.004} \\
\hline 1 & 41 & 21 & \\
\hline \multicolumn{4}{|c|}{ BRCA1 nucl } \\
\hline 0 & 14 & 4 & \multirow[t]{3}{*}{0.003} \\
\hline 1 & 72 & 67 & \\
\hline 2 & 10 & 25 & \\
\hline \multicolumn{4}{|c|}{ BRCA1 cyt } \\
\hline 0 & 14 & 26 & \multirow[t]{2}{*}{0.038} \\
\hline 1 & 81 & 69 & \\
\hline \multicolumn{4}{|l|}{ Wwox } \\
\hline $1-2$ & 26 & 87 & \multirow[t]{2}{*}{$<0.00001$} \\
\hline $3-4$ & 62 & 1 & \\
\hline
\end{tabular}

* $P$ value from McNemar's test to evaluate paired categorical outcomes and a measure of agreement between the tumor and metastatic tissue expression profiles; ErbB3, Ap $2 \alpha / \gamma$, pChk2, $\gamma \mathrm{H} 2 \mathrm{AX}$, Fhit, p53, and EGFR did not show significant differences in expression in primary tumor vs. metastasis. ErbB2 data was not available for the metastases. There were differences in frequencies of specific subtypes among the non-metastatic (luminal 83\%, ErbB2+++ 7\%, TN 10\%) vs. metastatic (luminal $72 \%$, ErbB $2+++10 \%$, TN 18\%) primary cancers

\section{Associations of markers and outcomes}

For a subset of 330 patients, there was recurrence data available; 60 distant and 19 locoregional. Patients who developed in situ recurrences or had metastases at diagnosis were excluded from the disease-free status analyses. The resulting cohort used in the analyses was 305 nonmetastatic breast cancer subjects with data available on disease-free and recurrence status; 79 subjects had a recurrence and the median follow-up was 98 months (range: 4-242 months); only 8 subjects had $<12$ months follow-up.

Disease-free survival of TN cancers was significantly worse than for luminal subtypes (see Fig. 5), as expected from earlier studies (note that ErbB2+++ cases are from before introduction of trastuzamab treatment). DFS for TN cases vs. all other subtypes was also significantly worse $(P=0.0001)$ (Table 6). DFS of cases with reduced Fhit was significantly worse and this figure remained significant when Fhit negative and mild expressers were combined together vs. moderate plus high expressers $(P=0.007$, Fig. 6). DFS of cases with membrane ErbB4 expression 

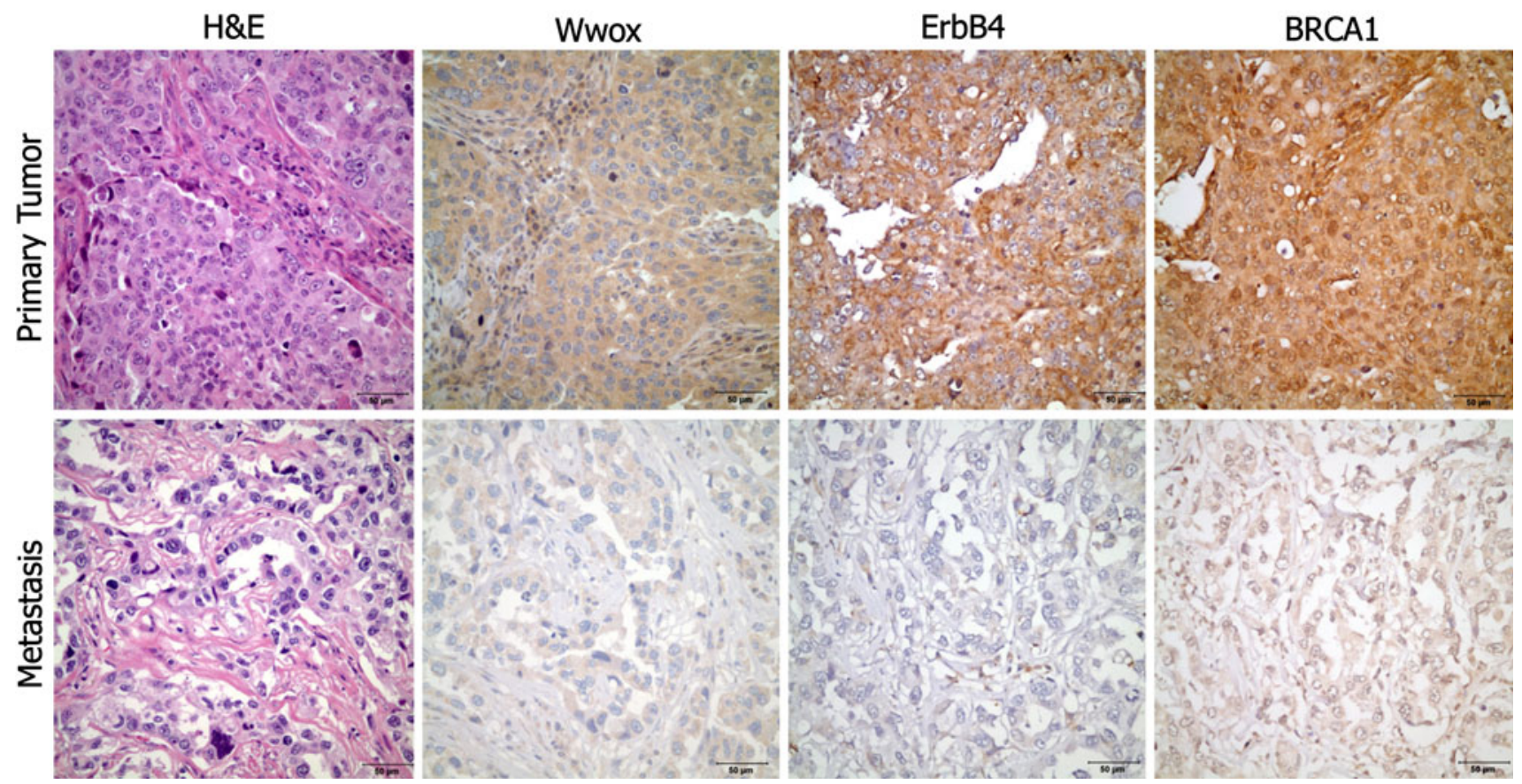

Fig. 4 Differentially expressed proteins in primary and metastatic breast cancers. Photographs $(\times 400)$ of differentially expressed markers in matched primary and metastatic lymph node cancer tissue from a single patient

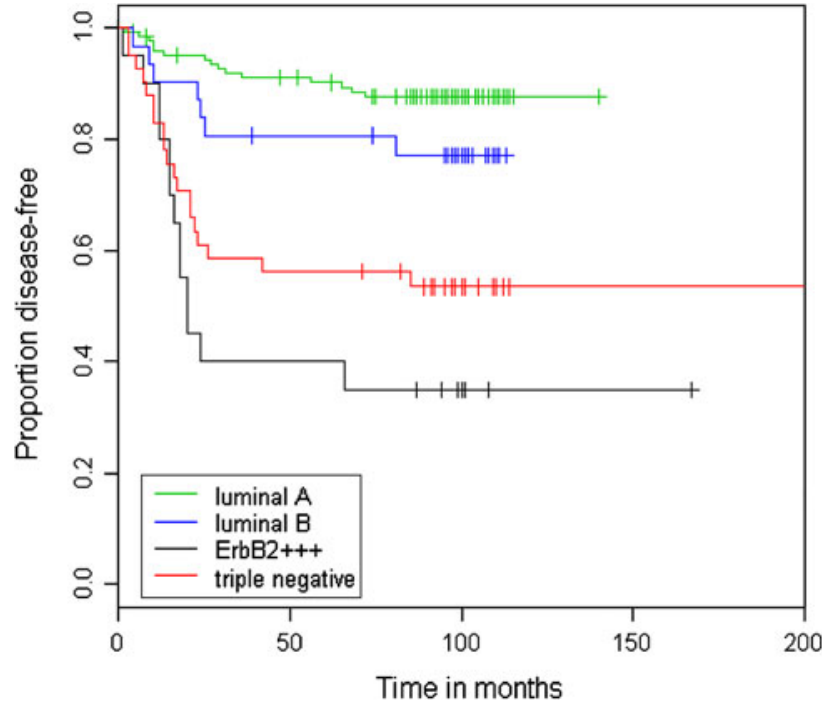

Fig. 5 DFS of patients with TN breast tumors. DFS of patients with TN breast tumors cohort was significantly worse than luminal subtypes or the other subtypes grouped together (not shown); also DFS for basal-like tumors was worse than other subtypes grouped together (not shown). Note that this TMA represents cases treated before the introduction of trastuzamab for ErbB2 +++ cases

was also significantly worse than others $(P=0.0013$, not shown).

In univariate analyses, the following factors/markers had a $P$ value $<0.20$ and were considered in the multivariable model: stage, grade, breast cancer subtype, ErbB3
Table 6 DFS in stage I-III cases at diagnosis

\begin{tabular}{lllll}
\hline Group & $\mathrm{N}$ & \# of events & HR & $P$ value \\
\hline Luminal A & 125 & 15 & Ref. & - \\
Luminal B & 31 & 7 & 1.98 & 0.14 \\
ErbB2+++ & 20 & 13 & 8.1 & $<\mathbf{0 . 0 0 0 0 1}$ \\
TN & 41 & 20 & 5.0 & $<\mathbf{0 . 0 0 0 0 1}$ \\
Luminal & 215 & 34 & Ref. & - \\
ErbB2+++ & 20 & 13 & 6.3 & $<\mathbf{0 . 0 0 0 0 1}$ \\
TN & 41 & 20 & 3.8 & $<\mathbf{0 . 0 0 0 0 1}$ \\
Luminal & 215 & 34 & Ref. & - \\
ErbB2+++/TN & 81 & 42 & 4.2 & $<\mathbf{0 . 0 0 0 0 1}$ \\
Not TN & 235 & 47 & Ref. & - \\
TN & 41 & 20 & 2.89 & $\mathbf{0 . 0 0 0 1}$ \\
Not basal-like & 243 & 53 & Ref. & - \\
Basal-like & 29 & 12 & 1.96 & 0.042 \\
\hline Ref reference & $1 . e .$, & & &
\end{tabular}

Ref reference group; i.e., the hazard ratios (HR) are in reference to this group. For example, if $\mathrm{HR}=2$, cases in that group are twice as likely to have an event than those in ref group; estimates from a Cox regression model

(cytoplasmic), ErbB4 (membrane), Fhit and p53; grade was highly correlated with stage $(P<0.00001)$ and with breast cancer subtype $(P<0.00001)$. To avoid multicolinearity issues, grade was excluded from the final multivariable model. Ultimately, the three significant factors in the model for DFS were stage $(P=0.00014)$, breast cancer subtype $(P<0.0001)$, and ErbB4 membrane score $(P=0.0065)$. 


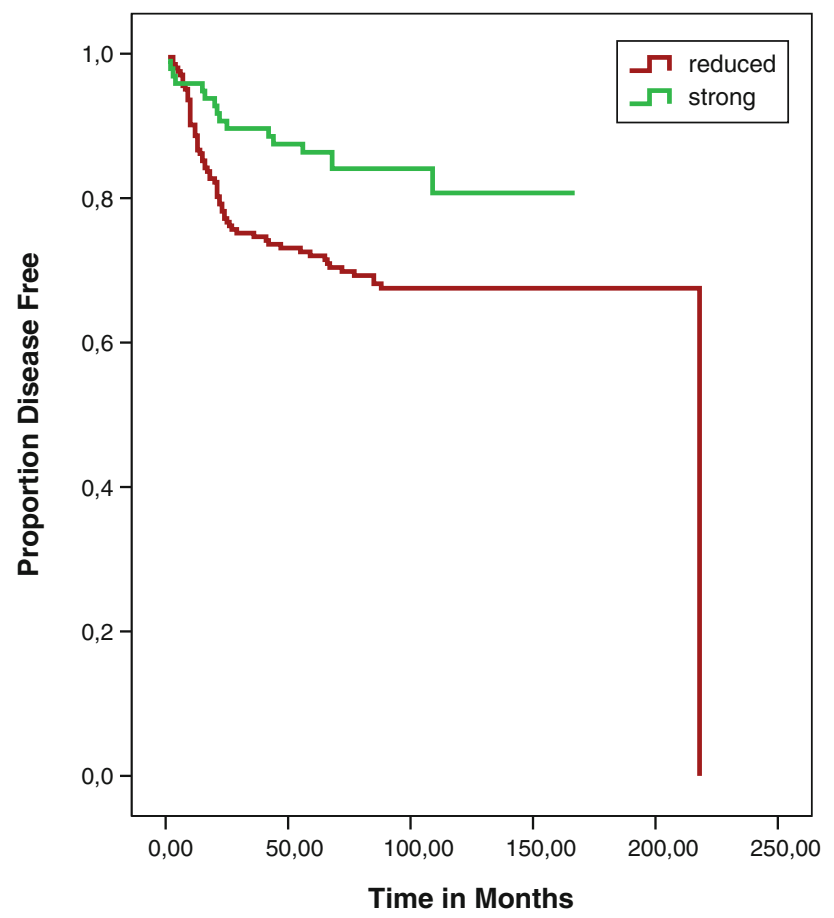

Fig. 6 DFS of breast cancers with low or no Fhit expression vs. cancers with moderate or high Fhit expression $(P=0.008)$

As described above, we created a DDR marker-based score that reflected the number of DNA damage response proteins with aberrant expression in each cancer. DFS of patients differed significantly depending upon the number of deleterious markers exhibited as shown in Table S3 and Fig. 7. Our analyses are limited by the large percentage of censored observations and the constraint that subjects needed to have data available on all five markers used to generate the DDR score.

\section{Discussion}

Associations among marker proteins

BRCA1 nuclear expression was strongly, positively associated with ErbB3 cytoplasmic expression, as well as with Fhit and Wwox expression; Fhit loss was correlated with expression of $\mathrm{p} 53$, and strongly, positively correlated with expression of cytoplasmic ErbB3 and ErbB4; p53 was most strongly correlated with expression of Ap $2 \gamma$; and Wwox loss was most strongly correlated with loss of expression of ErbB3 cytoplasmic protein and with Fhit loss. The unexpected strong correlation of Fhit expression with cytoplasmic ErbB4 and Ap2 $\alpha$, both Wwox interactors, and correlation of Wwox and Fhit with cytosolic ErbB3, warrant mechanistic studies in breast cancer-derived cell lines.

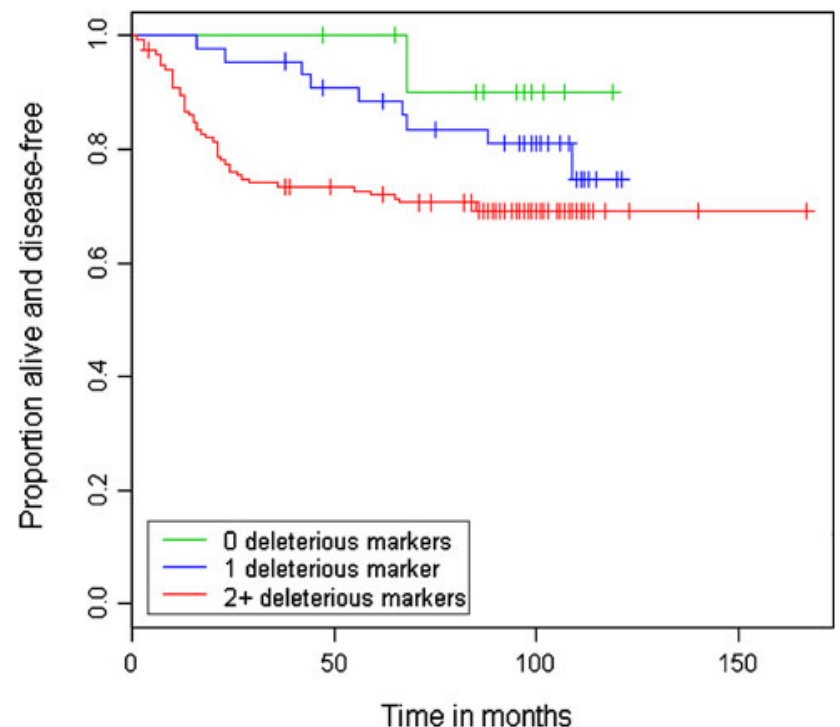

Fig. 7 DFS of patients based on breast cancer expression levels of DDR proteins. The DDR-associated proteins assessed and used in this DFS analysis were altered or activated expression of nuclear BRCA1, $\gamma \mathrm{H} 2 \mathrm{AX}, \mathrm{pChk} 2$, Fhit, p53; i.e., proteins involved in recognition of DNA breaks $(\gamma \mathrm{H} 2 \mathrm{AX})$, in checkpoint activation in response to breaks (pChk2, p53), or DNA repair (Fhit, BRCA1). It is likely that subtype is the driver of these differences because the DDR proteins tend to be most frequently altered in TN cancers, though the analyses are limited by the relatively large percentage of censored observations and the small numbers of cases in some subgroups, as illustrated in Table S3

\section{DDR-associated proteins and breast cancer subtypes}

Our studies show a previously unreported feature of TN breast cancers. Three proteins of the activated DDR checkpoint, $\gamma \mathrm{H} 2 \mathrm{AX}$, pChk2, and $\mathrm{p} 53$, are more frequently expressed in this group of neoplasms with $67 \%$ of pChk2 positive cases being $\gamma \mathrm{H} 2 \mathrm{AX}$ positive; and expression of BRCA1 and Fhit, associated with aberrant DNA damage repair, are highly significantly reduced in TN cancers. Interestingly, Fhit and BRCA1 are reduced in expression together in $70.9 \%$ of cases. We do not know if $\gamma \mathrm{H} 2 \mathrm{AX}$ and pChk2 expression together indicate an intact-activated checkpoint or if the $70 \%$ of $\gamma \mathrm{H} 2 \mathrm{AX}$ positive cases that are negative for pChk2 expression are evidence of a crippled checkpoint. It would be useful to examine subtype specific breast cancer cell lines with persistently activated checkpoints for sensitivity to inhibitors of Chk2 and Chk1. In addition, since absence of BRCA1 and Fhit are not correlated with activation of the checkpoint proteins, it may be that the BRCA1 and/or Fhit-deficient TN cancers are more likely to be sensitive to PARP inhibitors, as expected from previous studies [13, 14, 17].

So why are TN breast cancers, including the basal-like subgroup, more likely to show evidence of activated checkpoints, deleted fragile tumor suppressors, and DDR defects? It could be related to the cell type of origin for 
these cancers. Basal-like breast tumors are enriched in breast cancer stem cells [34-37], and p53 and BRCA1 proteins may have roles in stem cells [36, 37]. Presumably stem cells, including cancer stem cells, have a longer history of cell divisions than differentiated cells, providing many more opportunities for exposure to replication stress followed by repair defects and genome instability. TN cancers do show evidence of more genomic alterations than other breast cancer subtypes [38]. It has even been suggested that reduced expression of BRCA1 and Fhit may be hallmarks of stem cells [37, 39]. The persistent expression of DDR-associated proteins observed in this study in TN cancers probably has an important role in development of these cancers.

In a relevant example, Asakawa et al. [40] studied human breast cancer biopsies and showed that treatment with DNA damaging drugs induced nuclear foci of $\gamma \mathrm{H} 2 \mathrm{AX}$, conjugated ubiquitin, and Rad51 in a substantial fraction of cases. The presence of BRCA1, $\gamma \mathrm{H} 2 \mathrm{AX}$, or Rad51 foci before treatment was inversely correlated with tumor response to chemotherapy. DDR competence was further evaluated by considering all four repair indicators together. A high DDR score significantly correlated with low tumor response. The results "suggested importance of evaluation of DDR competence to predict breast cancer chemosensitivity..." [40].

Tumor suppressors and interactors in breast cancer subtypes

The most striking finding concerning Wwox expression was that nearly $100 \%$ of metastatic tissues showed lower Wwox expression than the matched primary tumors. This is of particular interest because recent studies have shown that siRNA-mediated knockdown of endogenous Wwox in ovarian cancer cells increased adhesion to fibronectin and $W W O X$-transfected cells in suspension culture displayed a proapoptotic phenotype. The authors proposed that Wwox acts as an ovarian tumor suppressor by modulating the interaction between tumor cells and the extracellular matrix and by inducing apoptosis in detached cells, suggesting a role for Wwox loss in peritoneal dissemination of ovarian cancer cells [41, 42]. Reduction of Wwox expression in metastatic tissues suggest a similar role for Wwox loss in lymph node metastasis. Expression of the Wwox-interacting protein, ErbB4, in membrane and cytosolic forms, was also significantly reduced in the metastatic lesions. Sundvall et al. [43] have reviewed aspects of ErbB4 expression and prognostic significance in breast cancer and have shown that absence of Wwox protein was associated with the number of cancer-positive axillary lymph nodes.

Ap2 $\alpha$ and $\gamma$ transcription factors have been implicated in control of proliferation, differentiation, and apoptosis of normal breast epithelium and in breast cancer. It is possible that the association of Ap2 $\gamma$ with $\mathrm{TN}$ cancers is related to the role of $A p 2 \gamma$ in proliferation of the mammary gland precursor cells. A recent study [44] showed that the WWOX gene is a transcriptional target of the Ap $2 \gamma$ transcription factor, suggesting an autoregulatory loop involving Wwox and Ap $2 \gamma$ proteins; thus, perhaps Wwox loss in TN cancers permits nuclear Ap2 $\gamma$ localization and upmodulation of proliferative activity.

\section{Clinical associations}

In this study, DFS of cases with ErbB4 membrane positivity and reduced Fhit was significantly worse than others, though expression of membrane ErbB4 has been associated with favorable overall survival in previous studies [45, 46]. Our current results showed that expression of both cytoplasmic and membrane ErbB4 was more frequent in TN/ basal-like tumors, and the membrane form was associated with worse DFS. Altogether, the results imply that assigning a singular "good or bad" role for ErbB4 in breast carcinogenesis is not straightforward [43].

Aqeilan et al. [46] assessed the clinical significance of the Wwox-ErbB4 association in $>500$ breast cancers. Loss of Wwox expression was associated with unfavorable outcome, co-expression of membrane ErbB4 and Wwox was associated with favorable outcome, compared with cases with membrane ErbB4 and no Wwox immunoreactivity. In our study, Wwox was lost in nearly $100 \%$ of the metastases, and reduced cytoplasmic ErbB4 was significantly associated with metastatic tissues. Other investigators have reported that the ErbB4 cytosolic form is associated with apoptosis and favorable outcomes [45, 47], results that seem consistent with our observation of loss of cytosolic ErbB4 in metastatic tissues. Thus, there was a strong association of loss of the Wwox signal pathway with breast cancer lymph node metastasis, a finding that is likely tied to the role of expression loss in allowing survival of tumor cells that have detached from basement membranes [41].

Acknowledgments Preliminary results of this study were presented at the 2010 USCAP Annual Meeting. We gratefully acknowledge the outstanding technical services of Susie Jones, Jason Bacher and David A. Kellough in the Pathology Core Facility of the Ohio State University, and Arda Günay, Ozlem Kalayci and Aybuke Kabaoglu of the Hacettepe University Department of Pathology, as well as the services of the Tissue Archive Shared Facility of the Ohio State University Comprehensive Cancer Center. We are especially grateful for the expert help of Sinan Ussakli in preparing files for statistical analysis and to Teresa Druck for help in editing and submitting the MS. Supported by US Public Health Service/National Cancer Institute Grants CA120516, CA132453, CA115965, pilot funding from the Molecular Biology and Cancer Genetics Program of the Ohio State University Comprehensive Cancer Center, Hacettepe University Research Fund Grant 05D11101003, and the Stephanie Spielman Foundation. 


\section{References}

1. Durkin SG, Ragland RL, Arlt MF, Mulle JG, Warren ST, Glover TW (2008) Replication stress induces tumor-like microdeletions in FHIT/FRA3B. Proc Natl Acad Sci USA 105:246-251

2. Tsantoulis PK, Kotsinas A, Sfikakis PP, Evangelou K, Sideridou M, Levy B, Mo L, Kittas C, Wu XR, Papavassiliou AG, Gorgoulis VG (2008) Oncogene induced replication stress preferentially targets common fragile sites in preneoplastic lesions. A genome-wide study. Oncogene 27:3256-3264

3. Guler G, Uner A, Guler N, Han SY, Iliopoulos D, Hauck WW, McCue P, Huebner K (2004) The fragile genes, FHIT and WWOX, are coordinately inactivated in invasive breast cancer: correlations with clinical features. Cancer 100:1605-1614

4. Guler G, Huebner K, Himmetoglu C, Jimenez RE, Costinean S, Volinia S, Pilarski RT, Hayran M, Shapiro C (2009) Fragile histidine triad protein, WW domain-containing oxidoreductase protein, and activator protein 2 gamma expression levels correlate with basal phenotype in breast cancer. Cancer 115:899-908

5. Guler G, Uner A, Guler N, Han SY, Iliopoulos D, McCue P, Huebner K (2005) Concordant loss of fragile genes, Fhit and Wwox, in breast cancer development. Pathol Int 55:471-478

6. Gorgoulis VG, Vassiliou LV, Karakaidos P, Zacharatos P, Kotsinas A, Liloglou T, Venere M, Ditullio RA Jr, Kastrinakis NG, Levy B, Kletsas D, Yoneta A, Herlyn M, Kittas C, Halazonetis TD (2005) Activation of the DNA damage checkpoint and genomic instability in human precancerous lesions. Nature 434:907-913

7. Bartkova J, Horejsi Z, Koed K, Krämer A, Tort F, Zieger K, Guldberg P, Sehested M, Nesland JM, Lukas C, Ørntoft T, Lukas J, Bartek J (2005) DNA damage response as a candidate anticancer barrier in early human tumorigenesis. Nature 434:864-870

8. Bartek J, Bartkova J, Lukas J (2007) DNA damage signalling guards against activated oncogenes and tumour progression. Oncogene 26:7773-7779

9. Sozzi G, Pastorino U, Moiraghi L, Tagliabue E, Pezzella F, Ghirelli C, Tornielli S, Sard L, Huebner K, Pierotti MA, Croce CM, Pilotti S (1998) Loss of FHIT function in lung cancer and preinvasive bronchial lesions. Cancer Res 58:5032-5037

10. Pichiorri F, Palumbo T, Suh S-S, Okumura H, Trapasso F, Ishii H, Huebner K, Croce CM (2008) The Fhit tumor suppressor: 'guardian of the preneoplastic genome'. Future Oncol 4:815-824

11. Cirombella R, Montrone G, Stoppacciaro A, Giglio S, Volinia S, Graziano P, Huebner K, Vecchione A (2010) Fhit loss in lung preneoplasia: relation to DNA damage response checkpoint activation. Cancer Lett 6:249-259

12. Ishii H, Wang Y, Huebner K (2007) A Fhit-ing role in the DNA damage checkpoint response. Cell Cycle 6:1044-1048

13. Farmer H, McCabe R, Lord CJ, Tutt AN, Johnson DA, Richardson TB, Santarosa M, Dillon KJ, Hickson I, Knights C, Martin NM, Jackson SP, Smith GC, Ashworth A (2005) Targeting the DNA repair defect in BRCA mutant cells as a therapeutic strategy. Nature 434:917-921

14. Bryant HE, Schultz N, Thomas HD, Parker KM, Flower D, Lopez E, Kyle S, Meuth M, Curtin NJ, Helleday T (2005) Specific killing of BRCA2-deficient tumours with inhibitors of poly(ADPribose) polymerase. Nature 434:913-917

15. Rowe BP, Glazer PM (2010) Emergence of rationally designed therapeutic strategies for breast cancer targeting DNA repair mechanisms. Breast Cancer Res 12:203-214

16. Tan AR, Swain SM (2008) Therapeutic strategies for triplenegative breast cancer. Cancer J 14:343-351

17. Fong PC, Boss DS, Yap TA, Tutt A, Wu P, Mergui-Roelvink M, Mortimer P, Swaisland H, Lau A, O'Connor MJ, Ashworth A, Carmichael J, Kaye SB, Schellens JH, de Bono JS (2009)
Inhibition of poly(ADP-ribose) polymerase in tumors from BRCA mutation carriers. N Engl J Med 361:123-134

18. Alli E, Sharma VB, Sunderesakumar P, Ford JM (2009) Defective repair of oxidative DNA damage in triple-negative breast cancer confers sensitivity to inhibition of poly(ADP-ribose) polymerase. Cancer Res 69:3589-3596

19. Turner N, Tutt A, Ashworth A (2004) Hallmarks of 'BRCAness' in sporadic cancers. Nat Rev Cancer 4:814-819

20. Ingvarsson S, Agnarsson BA, Sigbjornsdottir BI, Kononen J, Kallioniemi OP, Barkardottir RB, Kovatich AJ, Schwarting R, Hauck WW, Huebner K, McCue PA (1999) Reduced Fhit expression in sporadic and BRCA2-linked breast carcinomas. Cancer Res 59:2682-2689

21. Turner BC, Ottey M, Zimonjic DB, Potoczek M, Hauck WW, Pequignot E, Keck-Waggoner CL, Sevignani C, Aldaz CM, McCue PA, Palazzo J, Huebner K, Popescu NC (2002) The fragile histidine triad/common chromosome fragile site $3 \mathrm{~B}$ locus and repair-deficient cancers. Cancer Res 62:4054-4060

22. Silva Soares EW, de Lima Santos SC, Bueno AG, Cavalli IJ, Cavalli LR, Fouto Matias JE, de Souza Fonseca Ribeiro EM (2010) Concomitant loss of heterozygosity at the BRCA1 and FHIT genes as a prognostic factor in sporadic breast cancer. Cancer Genet Cytogenet 199:24-30

23. Li L, Zou L (2005) Sensing, signaling, and responding to DNA damage: organization of the checkpoint pathways in mammalian cells. J Cell Biochem 94:298-306

24. Kastan MB, Bartek J (2004) Cell-cycle checkpoints and cancer. Nature 432:316-323

25. Arlt MF, Durkin SG, Ragland RL, Glover TW (2006) Common fragile sites as targets for chromosome rearrangements. DNA Repair (Amst) 5:1126-1135

26. Fillingham J, Keogh MC, Krogan NJ (2006) GammaH2AX and its role in DNA double-strand break repair. Biochem Cell Biol 84:568-577

27. Deng CX (2006) BRCA1: ccll cycle checkpoint, genetic instability, DNA damage response and cancer evolution. Nucleic Acids Res 34:1416-1426

28. Sørlie T, Perou CM, Tibshirani R, Aas T, Geisler S, Johnsen H, Hastie T, Eisen MB, van de Rijn M, Jeffrey SS, Thorsen T, Quist $\mathrm{H}$, Matese JC, Brown PO, Botstein D, Eystein Lønning P, Børresen-Dale A (2001) Gene expression patterns of breast carcinomas distinguish tumor subclasses with clinical implications. Proc Natl Acad Sci USA 98:10869-10874

29. Niland JC (1998) NCCN Internet-based data system for the conduct of outcomes research. Oncology 12:141-146

30. Guler G, Iliopoulos D, Guler N, Himmetoglu C, Hayran M, Huebner K (2007) Wwox and Ap2 $\gamma$ expression levels predict tamoxifen response. Clin Cancer Res 13:6115-6121

31. Nielson TO, Hsu FD, Jensen K, Cheang M, Karaca G, Hu Z, Hernandez-Boussard T, Livasy C, Cowan D, Dressler L, Akslen LA, Ragaz J, Gown AM, Gilks CB, van de Rijn M, Perou CM (2004) Immunohistochemical and clinical characterization of the basal-like subtype of invasive breast carcinoma. Clin Cancer Res 10:5367-5374

32. Cheang MC, Voduc D, Bajdik C, Leung S, McKinney S, Chia SK, Perou CM, Nielsen TO (2008) Basal-like breast cancer defined by five biomarkers has superior prognostic value than triple-negative phenotype. Clin Cancer Res 14:1368-1376

33. Furnival GM, Wilson RW Jr (1974) Regressions by leaps and bounds. Technometrics 16:499-511

34. Lim E, Vaillant F, Wu D, Forrest NC, Pal B, Hart AH, AsselinLabat ML, Gyorki DE, Ward T, Partanen A, Feleppa F, Huschtscha LI, Thorne HJ, ConFab k, Fox SB, Yan M, French JD, Brown MA, Smyth GK, Visvader JE, Lindeman GJ (2009) Aberrant luminal progenitors as the candidate target population 
for basal tumor development in BRCA1 mutation carriers. Nat Med 8:907-913

35. Smalley M, Ashworth A (2003) Stem cells and breast cancer: a field in transit. Nat Rev Cancer 3:832-844

36. Dontu G, El-Ashry D, Wicha MS (2004) Breast cancer, stem/ progenitor cells and the estrogen receptor. Trends Endocrinol Metab 15:193-197

37. Liu S, Ginestier C, Charafe-Jauffret E, Foco H, Kleer CG, Merajver SD, Dontu G, Wicha MS (2008) BRCA1 regulates human mammary stem/progenitor cell fate. Proc Natl Acad Sci USA 105:1680-1685

38. Linn SC, Van 't Veer LJ (2009) Clinical relevance of the triplenegative breast cancer concept: genetic basis and clinical utility of the concept. Eur J Cancer 45(Suppl 1):11-26

39. Ishii H, Mimori K, Ishikawa K, Okumura H, Pichiorri F, Druck T, Inoue H, Vecchione A, Saito T, Mori M, Huebner K (2008) Fhitdeficient hematopoietic stem cells survive hydroquinone exposure carrying precancerous changes. Cancer Res 68:3662-3670

40. Asakawa H, Koizumi H, Koike A, Takahashi M, Wu W, Iwase H, Fukuda M, Ohta T (2010) Prediction of breast cancer sensitivity to neoadjuvant chemotherapy based on status of DNA damage repair proteins. Breast Cancer Res 12:R17

41. Gourley C, Paige AJ, Taylor KJ, Ward C, Kuske B, Zhang J, Sun M, Janczar S, Harrison DJ, Muir M, Smyth JF, Gabra H (2009) WWOX gene expression abolishes ovarian cancer tumorigenicity in vivo and decreases attachment to fibronectin via integrin alpha3. Cancer Res 69:4835-4842

42. Zhang JQ, Li L, Song HL, Paige A, Gabra H (2009) Effects of WWOX on ovarian cancer cell attachment in vitro. Zhonghua Fu Chan Ke Za Zhi 44:529-532

43. Sundvall M, Iljin K, Kilpinen S, Sara H, Kallioniemi OP, Elenius K (2008) Role of ErbB4 in breast cancer. J Mammary Gland Biol Neoplasia 13:259-268

44. Woodfield GW, Chen Y, Bair TB, Domann FE, Weigel RJ (2010) Identification of primary gene targets of TFAP2C in hormone responsive breast carcinoma cells. Genes Chromosomes Cancer 49:948-962

45. Thor AD, Edgerton SM, Jones FE (2009) Subcellular localization of the HER4 intracellular domain, 4ICD, identifies distinct prognostic outcomes for breast cancer patients. Am J Pathol 175:1802-1809

46. Aqeilan RI, Donati V, Gaudio E, Nicoloso MS, Sundvall M, Korhonen A, Lundin J, Isola J, Sudol M, Joensuu H, Croce CM, Elenius K (2007) Association of Wwox with ErbB4 in breast cancer. Cancer Res 67:9330-9336

47. Feng SM, Sartor CI, Hunter D, Zhou H, Yang X, Caskey LS, Dy R, Muraoka-Cook RS, Earp HS 3rd (2007) The HER4 cytoplasmic domain, but not its $\mathrm{C}$ terminus, inhibits mammary cell proliferation. Mol Endocrinol 21:1861-1876 